keywords: territorial: conjugation, knowledge, integrative economy, knowledge-based innovation area, innovation potential, territorial development strategy

\title{
TERRITORIAL CONJUGATION AND GENERATION OF KNOWLEDGE-BASED INNOVATION AREA ${ }^{1}$
}

The paper deals with the issues concerned with junction process influence on the character of territorial development. The process of generation of new activities is demonstrated, including territorial conjugation and integrative economy. Emergence of new self-sustained economic resources for territorial development is demonstrated; the key resources are knowledge-based and innovation potentials; in

${ }^{1}$ The paper is completed with financial support from the project №09-П-6-1003 “The principles of generation and operation of self-developing economic systems..." implemented within the framework of the Programme by the Presidium of the RAS № 29. connection with that, territories acquire new quality specified as a knowledge-based innovation area.

\section{Urgency of the issue}

The modern world undergoes gradual integration of isolated structures and processes (industrial enterprises, technologies, markets, territories) into a united and coordinated phenomenon. Such kind of reorganization on the global market is specified by the concept of globalization.

Various junction processes occur in local territories as well. This is reflected in the fact that 


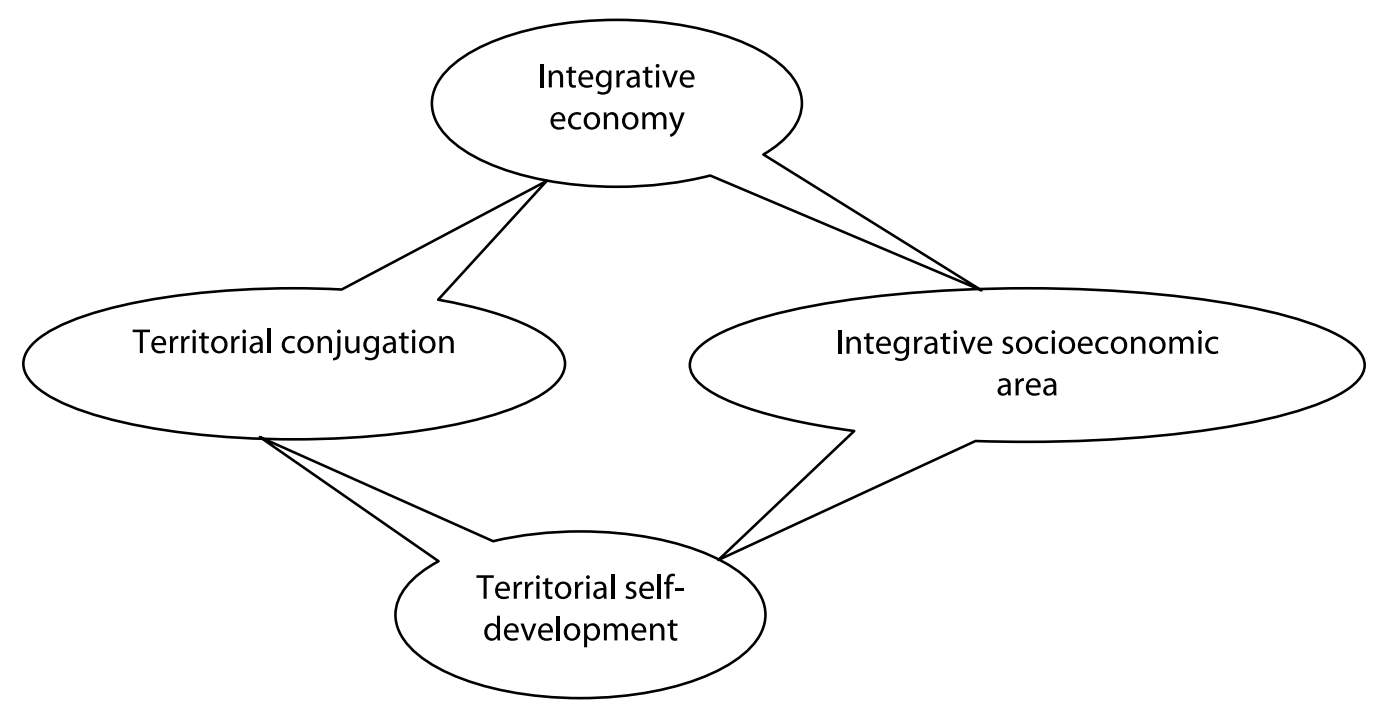

Fig. 1. Interdetermination of emergence of new phenomena in the process of territorial self-development

interrelationship of different factors is enhanced, impact on territorial development of cultural, educational, information exchange is intensified, personal socialization grows. Taken as a whole, the given processes allow territorial development turning into a targeted process of reproduction of people-as-personalities as a major treasure for a territory, i. e. into the process that is not reduced only to satisfying the requirements of the people, but extended to building up relations specific of a civil society. A considerable part of the given junction processes are related to the concept "territorial self-development".

The basis for current activization of the processes referred to self-development and area reorganization is people's knowledge of social, cultural, economic and other facts, and this knowledge is applied for economic activity. It allows giving an insight into socioeconomic aspects, and such knowledge can act as a strategy of territorial development.

Along with that, the developing conjunctive processes remain unstable due to individual (personal and corporate) liberty of their participants. Destabilization of relations inevitably increases without necessary institutions (regulatory or ethical), which consolidate norms and regulations referred to concordant behavior.

Economic conversion in local territories increasingly draws attention of social scientists. However, an insight into the given process is complicated, on the one hand, by immaturity of newly-formed parties in the context of development and self-development of territories, which affords no opportunity to see the substance of causal connections to the full extent; on the other hand, by inferiority or scarcity of the existing research tools, and often total lack of them.
Due to the lack of relevant concepts and categories, researchers are not always capable of both properly explaining current processes of municipal development and self-development in available terms, and correctly describing newly-emerging features and characteristics of socioeconomic phenomena with already existing concepts.

Therefore, researchers of territorial development character face a dual-purpose task, which involves not only conducting an in-depth study of new phenomena, including conjunctive processes in territories and institutions related to them, but also creating proper tools to perceive and explain emerging innovations.

In our opinion, objective conjunctive processes taking place in a territory may affect, and they actually affect, emergence of new socioeconomic phenomena, which are subject to a specific study (figure 1).

Let us consider in more detail the essence and peculiarities of emergence of such phenomena as territorial conjugation, integrative economy, integrative socioeconomic area in a territory in the process of its self-development.

\section{Territorial conjugation, or juncture of complexes}

A major problem in reference to territorial development at present is particular concurrence (consensus) of people's multiple actions in the context of life arrangement. Population, businessmen, State authorities, social structures continuously come into mutual contact. They conclude and dissolve agreements, supply products, make payments, render educational, cultural, research and medical services.

The purpose of science is finding among such diversified actions the fundamentals common for 
the given actions in order to establish regularity in terms of development of such processes and feasible control over them. As was noted by A. A. Bogdanov, a well-known Russian economist and philosopher, the author of the famous "Tectology" (19121922), the great variety of actions both in practice and thinking is reduced to implementation of only two acts: conjunction and disjunction of available elements. Therewith, the two given acts are of unequal importance in human activity. One of them is basic, and the other is derivative. Along with that, there can be no totally independent disjunction act, which would not be associated with the conjunction act in one way or other.

In the processes of self-preservation and self-development of any phenomena the fact of conjunction is primary, and disjunction is always a consequence, it is secondary. A. A. Bogdanov illustrates explanation of the given phenomenon with a great number of examples taken from life and nature. Thus, before cutting a piece of wood or breaking it, the item being split is indispensable to be contacted either with the tool, or body organs, i.e. to perform an act of association and make a certain effort; breaking of bond of the item is accomplished only as a consequence of the given conjunction, as an act of secondary nature. "Therefore, - A. A. Bogdanov continues, - the primary element generating change, emergence, destruction, development of organization forms, in other words, the basis for the generating mechanism of tectology, is juncture of complexes. We shall denote it with a term taken from biology, which has more profound meaning and international application, - conjugation (italics by A. A. Bogdanov)” [1, p. 88].

A. A. Bogdanov considered the concept of "conjugation" to possess properties of generality, and in the given form it acts as a mechanism of emergence of new forms in the nature and society. He wrote that conjugation is cooperation and other kinds of communication, for instance, conversation; juncture of concepts and ideas; encounter of images or aspirations in the scope of consciousness; alloyage of metals; electric discharge between two bodies; and exchange of produce between enterprises.

According to A. A. Bogdanov, conjugation in essence is juncture of complexes. However, this is not mechanical juncture that results in multiplied repetition of old forms, but juncture that is of creative origin. Juncture of complexes inevitably results in the fact that a newly created form possesses combined properties (by heredity from each complex); owing to that, such juncture appears as the art, generation of new forms, which had never existed before.
In order to solve the task referred to implementation of juncture processes in a territory and application of strategic development hereinafter, we consider it possible to apply the term "conjugation" to territorial development, as a category "territorial conjugation". The basis for it is an idea of creative juncture of complexes, but it is applied to territorial development. Territorial conjugation is referred to as unconstrained and taskoriented interaction of economic, governmental, public and other entities operating in a territory and generating new approaches, goals, tasks and basic lines of territorial development in the process of creative application of the system of factors, conditions and relations.

Territorial conjugation in a theoretical and methodological aspect allows, on the one hand, making analysis into interaction of entities, which operate within the bounds of municipal government as a multitude of autonomous activities; on the other hand, considering inter-municipal relations as a many-sided integrality in the context of relationship with external environment.

So far as activity aimed at territorial selfdevelopment was secured, it is essential to integrate efforts by all the entities operating within the given socioeconomic area. Therefore, territorial conjugation is not only to reflect a character of such a process, but also specify a degree of concurrence of actions by the participants of territorial development.

Territorial conjugation, covering and integrating various socioeconomic actions within a municipal entity, acts as a mechanism of emergence of new forms of coordinated strategic actions by territorial development entities. It has high methodological and organizational potential, which provides emergence in the territory both of socioeconomic life patterns, which already exist in other places, for instance, private-public partnership, and new ones, which had never been applied before, for instance, private-municipal partnership.

The concept of territorial conjugation is relative but not equal to the concept of "territorial social organization", which denotes spacial organization of people's life established at a particular stage of socioeconomic development. Territorial social organization is formed in the course of settlement in an area and industrial development of the given area. It includes accommodation of population, production and non-production industry sectors, environmental management, territorial differentiation of labour, economic or national-ethnic zone division. It also involves the sum of the processes or actions that have an impact on the territorial social organization. Territorial conjugation allows for all the factors 
mentioned and it is generated on the basis of them. The main difference of territorial conjugation from territorial social organization is the fact that it "switches on" and activates the process (procedure) of emergence of new economic forms. It can be said that territorial conjugation is both a conceptual approach and a methodology for generation of new economic phenomena.

In reference to methodology, combination features referred to elements-activities are specific of territorial conjugation. A. A. Bogdanov distinguishes three possible cases of conjugation, which can be applied to territorial conjugation to the full extent.

The first case consists in the following: activities of two complexes are combined in such a way, that they do not become "antagonists" to one another, and consequently they do not bear any "losses". As a result, the ultimate positive effect is produced. However, the given case is merely theoretical. In actual practice ultimate harmony of activity combination cannot be achieved; it is impossible that no part of them appears as an antagonist to the other.

The second case is diametrically opposed: activities of one complex become total antagonists to activities by another complex; they completely paralyze them or are paralyzed by them. However, the direction of activities by two complexes will never be entirely opposed. Therefore, provided their equal amount, they cannot paralyze or neutralize each other completely. On the other hand, with excess of activities of one direction, activities of the other are neutralized.

The third case is the most regular: two complexes are combined in such a way, that their elementsactivities partially adjoin, partially they are mutual antagonists, i.e. they are organizationally deduced. One correlation normally prevails, and general nature of the combination depends on it [1, p. 89-90].

In all the three cases the sum total ("analytical sum", according to A. A. Bogdanov) as a result of combination of specific activities or corresponding antagonisms can be equal to an arithmetic sum of the activities combined, to be less, or to exceed arithmetic summation of previous actions.

The given general scientific metrological statements allow drawing a substantial conclusion regarding self-organization of economic processes. It consists in the fact that emergence of new economic forms is a natural and regular process. However, functional directivity of the given forms - positive or negative - is determined by the content and structure of complexes participating in conjugation. For instance, high efficiency of territorial development can be achieved both by way of forced use of resources, and through free market relations. Actual availability and efficiency of future economic forms can be assessed and predicted only by means of separation of complexes participating in conjugation and setting direction of activity for each of them, activities - on one side, antagonisms - on the other.

Undertheinfluence of avariety of multidirectional factors the emerging form accumulates specific features of each complex participating in conjugation. Within a certain period the form (system) acquires a critical value of particular properties. The form (system) changes from the state of a certain balance of the given properties to the state of prevalence of some of them. The given critical value of stability threshold is referred to as a bifurcation point. Subject to a degree of prevalence of certain properties, the form (system) can be specified by different states, i.e. it can approximate positive or negative functional directivity to a greater or lesser extent.

Applied to economic self-organization, this means that economic forms favoring economic advance can appear in the process of conjugation, as well as those, which parasitize on the economic organism and render unbalance and destruction.

It is essential to emphasize the fact that both forms are not of external origin, but they are the result of determinate combination by the people of national, regional and local components. Everything depends on specifics of their combination, as well as on combination of their elements and properties. Pyramid schemes, oligarchic structures and executive establishments for economy - all that emerged in presence of the same nationals, land, plants and factories, engineering system of natural gas pipelines, water facilities, communications, transportation and telecommunications. Therefore, everything depended on conditions created by people, and conditions, under which activity referred to generation of new economic forms took place. It was particularly those people (authorities, business, society), not some supreme power, who secured prevalence of specificc properties in the new forms.

\section{Emergence of integrative economy}

Territorial conjugation as a creative process related to combination of complexes results in emergence of a new phenomenon referred to as "integrative economy". Emergence of the given phenomenon in people's economic life is concerned with civilization transformations at the end of XX the beginning of XXI century, and it is a response to socioeconomic challenges of the present. 
Integrative economy is a consistent combination of preferences by personalities and the civil society of intelligent people. Integrative economy is not a process of combination or cooperative complementarity of tangible assets and labor efforts in the course of production and disposal of amenities (services), but unenforced, conscious and mutually beneficial behavior by people of education and culture, who aspire for life improvement of the society. Integrative economy is a new society that develops on the basis of wide application of knowledge, ethic and cultural norms in all scopes of activity people are engaged in.

The substance of integrative economy is not goods and services, but preferences of people and members of the society (alias economic agents, alias producers and consumers) in terms of the choice of production and consumption (use) items. People choose not only goods and services. Along with that, they choose the way of living, the main features of goods and services' production (for instance, environmentally friendly or pollutant production), the main features of organization of yards, child day care centers (from the point of view of range and quality of services), living conditions and recreation activities. The choice is made based on the preferences generated in the family, school, in the course of communication with other people, under the influence of literature, art, advertising. It results in formation of dispositions and habits. Taken together, it is the result of social and cultural development of the society, reflection of knowledge and perception, or the set of intellectual values. Therefore, integrative economy refers its transformations, uppermost, to change in people's apprehension regarding mode of behavior and life.

In terms of methodology, the idea about the structure of integrative economy bears on broader understanding of major structural elements of the society, which are developed by researchersin the field of social and political science. One of the founders of the social stratification theory, an acknowledged sociologist Pitirim Sorokin distinguished three given elements as a framework. He wrote: "...The sociocultural interaction structure, if viewed from another angle, has three aspects, which are inseparable from each other:

1) personality as a subject of interaction;

2) society as an aggregate of interacting individuals, socio-cultural relations and processes;

3) culture as an aggregate of values and standards applied by interacting individuals; an aggregate of bearers, who reveal the given values and make them unprejudiced and social” [2, p. 218].
Based on the mentioned sociological and structural aspects, let us single out three component and structural elements relative to integrative economy, which lie at the root of providing self-consistent combinations of preferences by individuals and society, and which gradually become peculiar of the present-day economy of any country or particular territory.

First, people of high intellectual level, general culture and education. Subject to the quality of the given element in the given territory, either development of science and new technologies becomes possible, or only adopted technologies are assimilated. In order that positive processes were consolidated and intensified in a territory, intelligent people have not only to know the laws related to development of the nature and society, but also to be at a high cultural level, be tolerant and capable of pursuing not only their own interests, but also the interests of the community. In other words, principles of a civil society should exist. With proper legislation they secure establishment of partnership relations between all participants of socioeconomic relations in a territory.

Second, regular economic development of a territory should indispensably involve a real production sector. This means that natural products are to be produced using territory's own resources; territory's demand in the given products has to be satisfied; and a part of the given amenities is to be sold with the purpose to get other amenities in return. No territory will survive without development of a material sector under market relations. It is an illusion that someone will create a required product and bring it to local residents. It should be understood that humans as biological matter cannot take nourishment only in the form of virtual information; they need real fat, protein and carbohydrates. There should be a place to produce them. In case if all territories (we could assume it) stop producing material values, hoping that others will do it and implying that those who produce them are less intelligent and, therefore, they will do it, the time of educated but hungry sybarites will inevitably come. Material production was always the basis for physical survival of humans and it will always be the same.

Third, any standard territorial economy requires an innovative service sector. Alternatively, lop-sided economic development of the territory takes place, the same as in case when a real sector of economy does not exist, which was mentioned above. A service sector involves not only service industries, i. e. those concerned with service activities related 
to manufactured or imported production, but also all the non-material sectors:

- transportation within and beyond a territory;

- tourist service; energy and telecommunication sector operation;

- legal service;

- book-keeping consulting;

- education and medical service;

- municipal and housing services.

Integrative economy is based on a number of fundamental principles. First, it requires analysis of territorial socioeconomic development performed in conformity with the principle of unity of economic and ethic-cultural approaches. The given principle consists in necessity to allow for a role and position of ideology, social values, various standards and common conventions, population's mentality when making economic decisions.

Another principle of integrative economy development is a principle of cumulativeness and synergism. Various socioeconomic and other factors have a cumulative effect on territorial development; they act as an integrated power, which results in intensification of the effect compared to individual actions by one factor. Secondary and tertiary changes enhance the primary and generate a kind of a living system, which independently finds internal sources and reserves for constant movement, i.e. self-development of socioeconomic system occurs.

The theory of integrative economy is based not on moral postulates, but it allows for them as market development components. It does not bring economy under the moral system; it integrates them both as an equal motive power that functions in the context of real (not forced) voluntary exchange. Therefore, the theory of integrative economy is based on the statements of both standard and positive economics. To be more precise, it is based on newly established behavioral economics, which is represented by a wellknown American economist, George Akerlof, the Nobel Laureate 2001 in Economics. Fundamentals of the given theory are set forth in the work "Spiritus Animalis" (the way human psychology controls economy and the reason why it is substantial for world capitalism [3, p. 17]. The essence of the given fundamentals is reduced to perception of a human being as a matter, which is guided by the irrational principle in economic activity, i.e. subjective factor of economic behavior is the major ${ }^{1}$.

\footnotetext{
${ }^{1}$ The authors clarify that the notion "Spiritus Animalis" comprises all unregulated and irrational aspects of economy and also those specifying our conduct in confusing or uncertain conditions. They say that previously the given word-group implied in Classical and Medieval Latin the meaning "life-giving" or "inherent in a soul" and signified spiritual energy and vitality.
}

Significance of integrative economy is in the fact that it extends human capability to rise both personal and social well-being through participation in development and implementation of new efforts adoptable for a territory. Another utility of integrative economy is the fact that it is not restricted only to change in technological and economic parameters in the process of development, but it involves the whole system of socioeconomic relations.

Integrative economy related to modernization includes alteration of an individual as a personality with his mentality and moral values, i.e. it is aimed at transformation of all spiritual aspects of life of a local community. This signifies that modernization relations should cover not only production proper, but also all economic, legal, psychological and ethic institutions.

Moral and cultural relations play exactly the same role in the newly-emerging integrative economy as economic relations. A man of education not just gets food as a source of life prolongation, but for the purpose of personal development, which is possible only through contacts with other such personalities.

Culture, economy, law, ethics become integral parts of the civilization, similar to an individual himself with spiritual and material values. Integrative economy is aimed at actual exaltation of an individual by withdrawing him from the state of being an appendix of economic activity and transformation of economy proper into the tool of personal development.

A concentrated analysis of economic processes coupled with social and ethic approaches was carried out by Sergey Nokolayevich Bulgakov in his work "Philosophy of economy" (1912). He had demonstrated the fact that individual education that develops into education of the nation leads to generation of such material conditions, which allow implementation of spiritual development as an objective and essence of human life to the full extent. S. N. Bulgakov was the first who demonstrated in the context of economic research that economic activity is not one of the components of human life, which exists alongside with other components, but it acts as a human life proper, it becomes reproduction of them as a part of the nature; the only difference is the fact that in the nature dull intellect prevails, and in human activity the given intellect manifests itself as a conscious act that results in "hominization of nature" [4, p. 41].

Later, similar views on unity of economic, social, cultural and ethic processes were expressed by a German historian O. Spengler in his work "Decline of Europe" (1918-1922). He wrote that "...any economic life is an expression of spiritual 
life" [5, p. 501]. He considered that those, who pursue only economic benefit, cannot accomplish comprehensive activity, and will inevitably become a dummy in someone's game, will be deceived and betrayed.

Integrative economy lays the basis for detachment of a human being from commonplace day-to-day activities aimed at his survival, and switching to an economic process of spiritual and ethic existence of a personality.

\section{Generation of a knowledge-based innovation area}

Integrative economy generates integrative socioeconomic area. To comprehend it, two principal features of an area should be taken into consideration. The first one is area stratification caused by diversification of activity types. The second feature is combination (integration) due to information technology development [6, p. 35].

An integrative socioeconomic area as a system is specified by a multitude of subsystems, their fixed mutual order, coordination of actions and bias towards securing a certain balance. The major feature of the area is the fact that development is determined by knowledge, moral and spiritual quality of people who inhabit the given area.

A number of an area's subsystems may grow with enhancement of integrative economy relations; it highlights new elements-activities that secure coordinated development. We focus only on several areas, namely: economic, geographic, social, intellectual-innovation, and moral and spiritual (ref. fig. 2).

Each of the mentioned areas are worthy of particular consideration. However, we shall focus mainly on the issues related to the intellectualinnovation area, and other areas will be restricted only to definition of their essence.
Geographic area is normally referred to as a physical area of geographic phenomena and processes proper; yet there are adjusting interpretations, right up to the social sphere being included in it.

Social area is a system of relationships between people - individuals, groups of people, within groups.

Economic area, according to A.G. Granberg, is a saturated territory, which comprises multitude of objects and relationships between them: localities, industrial enterprises, economically reclaimed and recreation areas, transport and utility systems etc. [7, p. 25]. In turn, E.G. Animitsa and V.A. Suhikh refer to an economic area as a sphere of generation of material wealth, where consumer activity is realized. This is an economically reclaimed part of the territory, where production, allocation, exchange and consumption of goods and services is accomplished. Extension and compression, being specific of an area, are aimed at fast allocation of the created and accumulated wealth in the area $[8$, p. 44].

Integrative economy development calls forth moral and spiritual area as an independent phenomenon. It should be understood as a field where moral values, mental abilities, psychological features, ethic relationships, standards and rules of human conduct are concentrated and developed.

Intellectual-innovation area is such a structure, composition and combination of relationships between scientific and technological potential and particular activities aimed at its realization, which can secure unity of intellectual potential with innovation potential and have a positive socioeconomic effect. Along with that, an intellectual-innovation area should not necessarily be specified by high concentration of scientific potential. Initially, the mere fact of its existence in any form suffices.

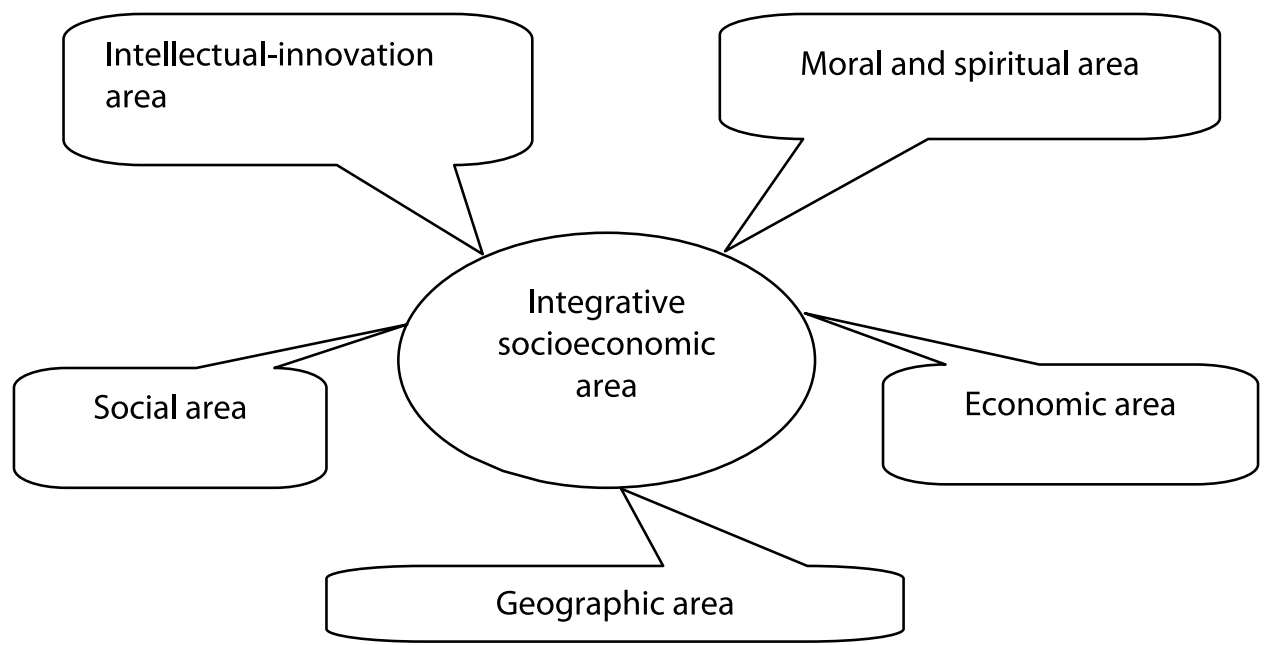

Fig. 2. Structure of integrative socioeconomic area 
Intellectual-innovation area is not an abstraction, but it is an actual intellectual-innovation state of a territory based on enterprises, libraries, schools, higher education institutions, health facilities etc., which secures diversification of local economy and generation of territorial innovation and technological sequences. One of the effects of generation and development of intellectual-innovation area will be emergence of such structures as science parks, industrial parks, technology parks, in which intellectual activity of the territory is realized.

Territorial innovations are not only structures and intellectual-technological sequences, but also features of human conduct, people's orientation towards target selection of movement, i.e. generation and implementation in a territory of moral, spiritual and economic values determining the meaning of human life.

Generation of intellectual potential of a territory is based on a complex human knowledge, which is generally diversified both in essence, and in terms of levels, types and quality. Such kaleidoscopic image of knowledge depends, first, on diversity of its carriers, which differ from each other in terms of age, professional occupation, cultural level. Second, colouring to the rainbow of knowledge is provided by objective factors referred to presence in a territory of educational and industrial structures, which generate demand for strictly definite knowledge, as well as a level of attraction of professionals from other regions to the territory. Third, level, diversity and directivity of knowledge in a territory depend on intellectual wealth, which was accumulated historically and inherited by the living generation from several previous generations of inhabitants.

Intellectual potential of a territory always has its material carrier represented by an individual himself. Along with that, people can realize it only in the context of the activity within the framework of particular structures.

The most common structures, under which territorial intellectual activity is accomplished, are: educational institutions (schools, colleges, higher education institutions), hospitals, libraries, legal services, industrial laboratories, control organs over enterprises and institutions, professional nonprofit associations, representative and executive bodies, public structures and their associations etc. They exist in any territory and act not only as intellectual centers, but also carry the function of cooperation of intellectual work of the occupied population, i.e. appear as an organizational, technical and economic base for intellectual potential application.

Intellectual potential leads to generation of high technologies, yield of knowledge-intensive production, transformation of industrial processes, and ultimately to alteration of people's way of living proper. The outcome of such changes is a new image of the territory, which is therefore perceived as a specific intellectual area with specific character. Such territories are often given original names. For instance, there is a Silicon Valley in the USA, Titanium Valley in the Sverdlovsk region in Russia etc.

The higher the intellectual potential of a territory, the more opportunities the population has to realize industrial activity including rendering services based on simplification of work, which assumes application of innovations referred to organization, institution, management and technology.

Intellectual potential generates ability to innovation thinking; this is the ability to retrieve new properties, features, connections from objects and phenomena. Innovation thinking is a way of thinking oriented towards positive changes through creation and application of innovations (technical, technological, organizational, economic etc.). Innovation thinking is search thinking in itself. We proceed from the fact that any territory with permanent residents and fully developed production, as well as actual social infrastructure, is specified by innovation thinking [9].

As a result of intellectual activity and innovation thinking, generation of innovation potential of a territory, i.e. a set of knowledge capable to be realized in the form of goods and services, occurs.

Generally, innovation potential of a territory is referred to as a complex of various resources to apply innovations for development. Let us emphasize three principal points to comprehend the idea of innovation potential of a territory.

First, specification of innovation potential should not be reduced to focusing on resources only, even if they are ready to be realized. Such an approach attributes a property of statics to innovation potential, emphasizes accumulation, "storage" of resources, which are in a way reserved, immobile, though intended for future application. In our opinion, the major feature of innovation potential is movement, i.e. not a static state, but dynamic, active, updating and reproducing. Innovation potential is the resources, which have come to the fore, i.e. resources waiting to be realized, the resources to be turned into reality. It can even be said that innovation potential is a kind of reformatory potential.

Second, innovation potential is in essence a process phenomenon concerned with generation and application of innovations. Innovation potential is conducive to innovations; therefore, it should be constantly updated, to be a living source of energy. 
Consequently, innovation potential cannot function in a still, mortified form. It always represents reviving and self-developing potential, i.e. it acts as an open, updating and extending system of knowledge.

Third, innovation potential is not random resources, but those mature, developed resources, acting as a future reality. The state of mature and necessary switching to reality is an essential feature of innovation potential. In case if scientific, technological and other advanced resources do not result in switching to reality, then accumulated knowledge can be considered rather as library, not innovation, potential.

Innovation potential is realized through innovation behavior and innovation economy.

Innovation behavior consists in such human actions and attitude to other economic and social entities, which, on the one hand, afford the economy and society an opportunity to develop in a civilized way; on the other hand, the given actions secure progressive development, which combines conventional methods of activity with advanced economic and socio-cultural ideas.

Innovation economy is a new type of economy, which is to be based not only on a unity of economic, environmental and socio-cultural development, but necessarily on their mutual supplement and entwinement. Innovation economy is in essence based on knowledge, but not of individuals or small groups, but on total intellect of the majority of economically active population.
Thus, so far as any territory possesses intellectual potential and innovation thinking, then theoretically any territory is capable of securing innovation development of production, service sector and social infrastructure.

\section{References}

1. Bogdanov, A. A. (2003). Tectology. General organizational science. Moscow: International Institute by Alexander Bogdanov, "Finance".

2. Sorokin, P. A. (1992). Structural sociology. Man. Civilization. Society. A. Y. Sogomonov (Ed.). Translated from English. Moscow: Politizdat.

3. Akerlof, G. \& Schiller P. (2010). Spiritus Animalis, or How human psychology administers economy and why this is important for world capitalism. D. Priyatkin (Transl.), A. Suvorov (Sc. ed.), S. Guriyev (Prol.). Moscow: United Press, ltd.

4. Bulgakov, S. N. (1990). Philosophy of economy. Moscow: Nauka (Science).

5. Spengler, O. (2003). Decline of Europe. I. I. Makhankova (Transl. from German), 2 Vols, Vol. 2. Moscow: Iris-Press.

6. Surnina, N. M. (2003). Spacial economy. Issues of theory, methodology and practice. E. G. Animitsa (Sc. ed.). Ekaterinburg: Ural State University of Economics Publ.

7. Granberg, A. G. (2000). Fundamentals of regional economy. University textbook. Moscow: Higher School of Economics.

8. Animitsa, E. G. \& Suhikh V.A. (2007). Space-time paradigm in socioeconomics: regional aspect. Perm: the Perm State University.

9. Bochko, V. S. (2008). Innovation thinking and innovation economy. Journal of Economics, 2, 38-50. 